\title{
Perancangan Dan Implementasi Sistem Informasi Pemasangan Baru PDAM Berbasis WEB
}

\author{
Dian Nurdiana \\ Program Studi Sistem Informasi Universitas Terbuka \\ dian.nurdiana@ecampus.ut.ac.id
}

\begin{abstract}
Regional Drinking Water Company (PDAM) is one of the regional-owned business units, which is engaged in the distribution of clean water to the general public. A company must be able to serve its customers to the maximum extent possible. However, in practice there are still many PDAMs in the regions that still serve their customers using a manual system, so there will be a buildup of documents and it will be difficult to find the documents needed. Included in the PDAM installation registration process, there are some who still use manuals. With this manual process, problems were found, such as uncontrolled registration or unknown distribution of customers who wanted to install a new PDAM. With the web-based PDAM installation information system an admin just needs to input the applicant's data which will install the web-based PDAM so that the data will be stored neatly in a database that is also easy to conduct data searches. From the results of the study concluded that the existence of this information system can provide convenience in processing data input and processing the date into a report so that the services provided by the PDAM are better.
\end{abstract}

\begin{abstract}
Abstrak - Perusahaan Daerah Air Minum (PDAM) merupakan salah satu unit usaha milik daerah, yang yang bergerak dalam distribusi air bersih bagi masyarakat umum. Sebuah perusahaan harus mampu melayani pelanggannya dengan semaksimal mungkin. Namun pada perakteknya masih banyak PDAM di daerah yang masih melayanin pelanggannya menggunakan sistem manual, sehingga akan terjadi penumpukan dokumen dan susah dalam pencarian dokumen yang di butuhkan. Termasuk dalam proses pendaftaran pemasangan PDAM, ada beberapa yang masih menggunakan manual. Dengan proses manual ini ditemukan masalah seperti tidak terkontrolnya pendaftar atau tidak diketahuinya sebaran dari pelanggan yang ingin memasang PDAM baru. Dengan adanya sistem informasi pemasangan PDAM berbasis web seorang admin tinggal menginputkan data pemohon yang akan memasang PDAM berbasis web sehingga data akan tersimpan rapih dalam sebuah database yang mudah juga untuk melakukan pencarian data. Dari hasil penelitian disimpulan dengan adanya sistem informasi ini dapat memberikan kemudahan dalam peroses input data maupun pengolahan date menjadi laporan sehingga layanan yang dilakukan PDAM menjadi lebih baik.
\end{abstract}

Kata Kunci : Sistem, Informasi, Pemasangan PDAM

\section{PENDAHULUAN}

Dalam Keputusan Menteri Dalam Negeri 47 Tahun 1999 tentang Pedoman Penilaian Kinerja Perusahaan Daerah Air Minum dijelaskan bahwa Perusahaan Daerah Air Minum selanjutnya disingkat PDAM adalah perusahaan milik daerah Propinsi atau daerah Kabupaten dan atau daerah Kota. Sedangkan menurut Idris (2007:2) PDAM adalah satusatunya perusahaan yang memonopoli produksi air minum secara masal. Oleh karena itu, perusahaan air minum harus selalu meningkatkan kinerjas agar kualitas air yang diproduksi sesuai dengan harapan pelanggan. Namun pada saat pendaftaran pelanggan baru masih banyak PDAM yang didaerah menggunakan sistem konvensional yaitu mengiput secara manual didalam kertas pedanftaran, hal ini menyebabkan data yang tidak rapih karena dengan sistem manual memungkinkan dat a tercecer sehingga bisa 
menghambat proses pemasangan pelanggan baru. Selain itu ketika pembuatan laporan pemasangan PDAM baru akan terkendala karena harus dilakukan dengan manual lagi sehingga memerlukan kerja lebih dari satu kali. Oleh karena itu berdasarkan permasalahan diatas maka penulis bertujuan membuat "sistem informasi pemasangan PDAM baru berbasis web" yang nantinya diharapkan dapat membantu proses pendaftaran sehingga bisa meningkatkan kepuasan terhadap pelanggan.

\section{A. Sistem}

\section{Kajian Teoritis}

Menurut Jogiyanto (2005:1), "Sistem adalah suatu jaringan kerja dari prosedurprosedur yang saling berhubungan, berkumpul bersama-sama untuk melakukan suatu kegiatan atau untuk menyelesaikan suatu sasaran yang tertentu'

\section{B. Informasi}

Menurut Jogiyanto (2005:8), "Informasi adalah data yang telah diolah menjadi bentuk yang lebih berarti dan berguna bagi penerimanya untuk mengambil keputusan masa kini maupun masa yang akan datang”.

\section{UML (Unified Modeling Language)}

Menurut Rosa dan Shalahuddin (2013:133), "UML adalah salah satu satu standar bahasa yang banyak digunakan di dunia industry untuk mendefinisikan requiretment, membuat analisis dan desain, serta menggambarkan arsitektur dalam pemrograman berorientasi objek"

\section{Metode Pengembangan Sistem}

Metode air terjun atau yang sering disebut metode waterfall sering dinamakan siklus hidup klasik (classic life cycle), dimana hal ini menggambarkan pendekatan yang sistematis dan juga berurutan pada pengembangan perangkat lunak, dimulai dengan spesifikasi kebutuhan pengguna lalu berlanjut melalui tahapan-tahapan perencanaan (planning), permodelan (modeling), konstruksi (construction), serta penyerahan sistem ke para pelanggan/pengguna (deployment), yang diakhiri dengan dukungan pada perangkat lunak lengkap yang dihasilkan (Pressman, 2012).

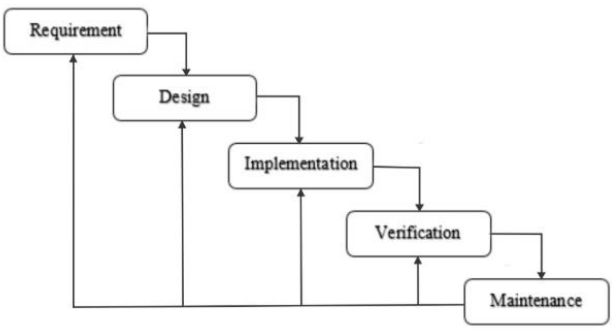

Dalam pengembangannya m etode waterfall memiliki beberapa tahapan yang berurut yaitu: requirement (analisis kebutuhan), design system (desain sistem), Coding (pengkodean) \& Testing (pengujian), Penerapan Program, pemeliharaan. Tahapan tahapan dari metode waterfall adalah sebagai berikut :

\section{Requirement Analisis}

Tahap ini pengembang sistem diperlukan komunikasi yang bertujuan untuk memahami perangkat lunak yang diharapkan oleh pengguna dan batasan perangkat lunak tersebut. Informasi ini biasanya dapat diperoleh melalui wawancara, diskusi atau survei langsung. Informasi dianalisis untuk mendapatkan data yang dibutuhkan oleh pengguna.

\section{System Design}

Spesifikasi kebutuhan dari tahap sebelumnya akan dipelajari dalam fase ini dan desain sistem disiapkan. Desain Sistem membantu dalam menentukan perangkat keras(hardware) dan sistem persyaratan dan juga membantu dalam mendefinisikan arsitektur sistem secara keseluruhan.

\section{Implementation}

Pada tahap ini, sistem pertama kali dikembangkan di program kecil yang disebut unit, yang terintegrasi dalam tahap selanjutnya. Setiap unit dikembangkan dan diuji untuk fungsionalitas yang disebut sebagai unit testing.

\section{Integration \& Testing}

Seluruh unit yang dikembangkan dalam tahap implementasi diintegrasikan ke dalam sistem setelah pengujian yang dilakukan masing-masing unit. Setelah integrasi seluruh sistem diuji untuk mengecek setiap kegagalan maupun kesalahan.

\section{Operation \& Maintenance}

Tahap akhir dalam model waterfall. Perangkat lunak yang sudah jadi, dijalankan serta 
dilakukan pemeliharaan. Pemeliharaan termasuk dalam memperbaiki kesalahan yang tidak ditemukan pada langkah sebelumnya. Perbaikan implementasi unit sistem dan peningkatan jasa sistem sebagai kebutuhan baru.

\section{E. PHP (PHP Hypertext Preprocessor)}

Menurut Paranginangin (2006:2), PHP singkatan dari PHP Hypertext Preprocessor yang digunakan sebagai bahasa script server- side dalam pengembangan web yang disisipkan pada dokumen HTML.

\section{F. MY SQL}

Menurut Rosa dan Shalahuddin (2013:46), SQL (Structured Query Language) adalah bahasa yang digunakan untuk mengolah data pada RDBMS (Relational

G. Web

Database Management System).

Menurut Supriyanto (2007), "Web adalah Jenis layanan koleksi keterhubungan dengan dokumen dokumen yang di simpan di internet dan diakses menggunakan protocol (HTTP) HyperText Transfer Protocol yang akan menghasilkan fasilitas informasi atau dokumen yang dapat diakses, dapat berupa data,

teks, gambar, suara, video dengan di perlukan web browser internet untuk menulis alamat di Internet Explorer, Netscape, Opera, Mozila Firefox, dan Google Chome".

\section{H. Xampp}

Adalah web server yang mudah digunakan untuk menampilkan halaman web yang dinamis

\section{Pengujian Black Box}

Menurut Rosa dan Salahuddin (2013:275), Pengujian black-box dilakukan dengan membuat kasus uji yang bersifat mencoba semua fungsi dengan memakai perangkat lunak apakah sesuai dengan spesifikasi yang dibutuhkan. Kasus uji yang dibuat dengan kasus benar dan kasus salah, misalkan untuk kasus login maka kasus uji yang dibuat adalah:

1. Jika pengguna memasukkan nama pengguna (username) dan kata sandi (password) yang benar;

2. Jika pengguna memasukkan nama pengguna (username) dan kata sandi (password) yang salah, misalnya nama pengguna benar tetapi kata sandi salah atau sebaliknya atau keduanya salah.

\section{METODE PENELITIAN}

\section{A. Tahapan Penelitian}

Tahapan penelitian merupakan gambaran jalannya penelitian, sehingga dari tahapan ini nantinya akan tergambar jelas apa yang akan dilakukan dalam penelitian ini. Adapun tahapan penelitian tersebut dapat dilihat pada Gambar dibawah ini .

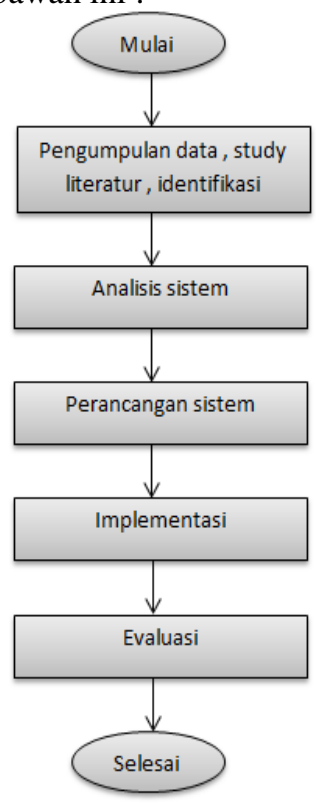

Gambar 2 Alur Metode Penelitian

B. Use Case Diagram

Use case diagram sistem informasi pemasangan PDAM

baru berbasis web .

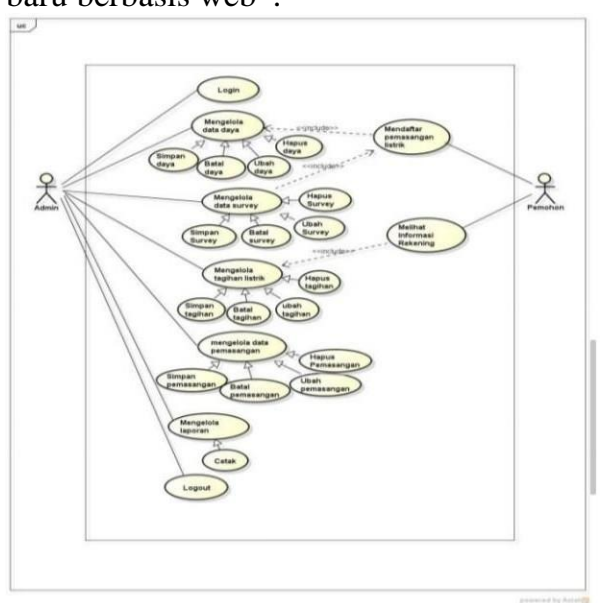

Gambar 3 Usecase Diagram

\section{Class Diagram}

Diagram Kelas atau Class Diagram menggambarkan struktur sistem dari segi pedefinisian kelas-kelas yang akan 
dibuat untuk membangun sistem. Clas Diagram tersebut dapat dilihat pada Gambar 4.

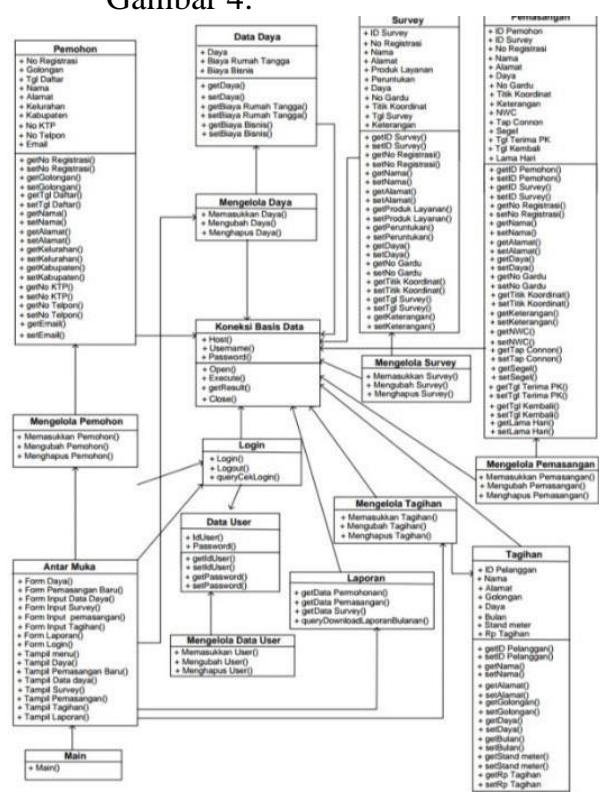

Gambar 4 Class Diagram

\section{Activity Diagram}

Activity diagram pada sistem informasi pemasangan ini menggambarkan workflow (aliran kerja) atau aktivitas dari sebuah sistem tersebut dan menggambarkan aktivitas apa yang dapat dilakukan oleh sistem informasi pemasangan PDAM. Adapun Activity Admin dan Pemohon dapat dilihat pada gambar dibawah ini .

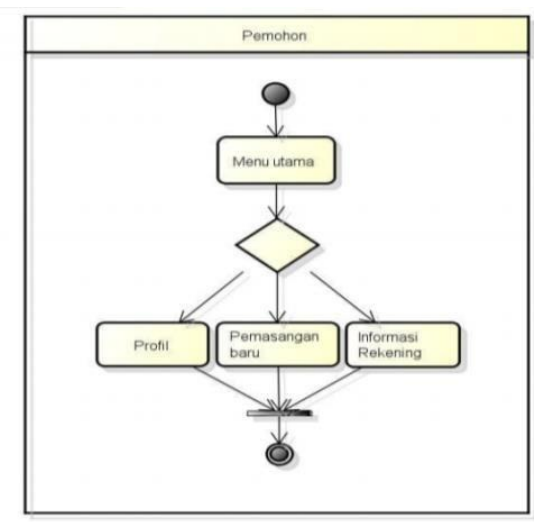

Gambar 5 Activity Diagram

\section{HASIL DAN PEMBAHASAN}

\section{A. Form Menu Utama}

Form menu utama merupakan tampilan pertama pada saat program dijalankan. Form menu utama ini, berfungsi untuk mengakses menu-menu lainnya yang terdapat pada program. Adapun Form Menu Utama bisa dilihat pada gambar dibawah ini .

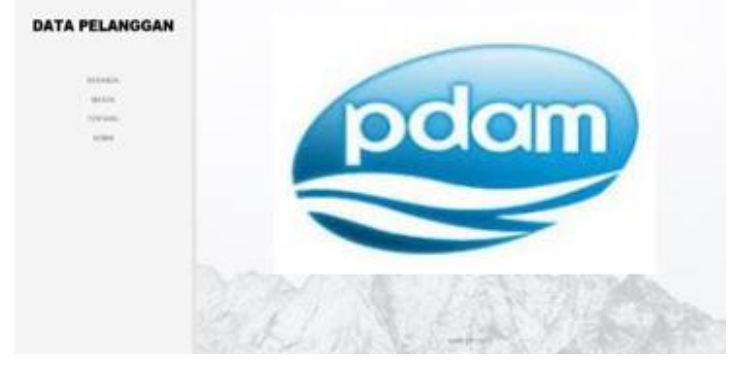

\section{B. Form Login}

Gambar 6 TampilanUtama

Form login merupakan tampilan awal untuk masuk ke dalam sistem informasi pemasangan PDAM baru tetapi hanya untuk hak akses bagian perusahaan atau admin yang bisa masuk dengan cara menginputkan username dan password dengan kata admin selain admin aplikasi ini tidak bisa dijalankan oleh seseorang yang tidak berhak menggunakannya.

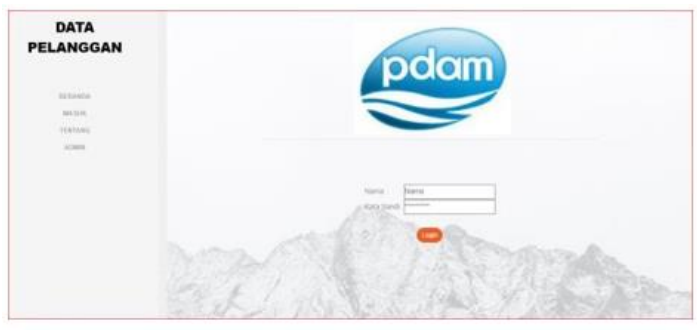

Gambar 7 Tampilan Login

\section{Form Admin}

Form admin merupakan form yang mengelola sistem tersebut

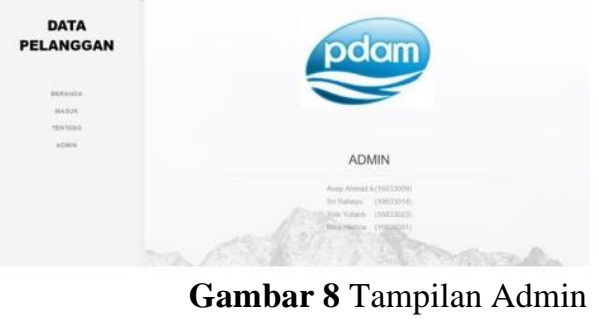

D. Form Tentang

Form tentang merupakan form tentang sistem pemasangan baru PDAM berbasis web .

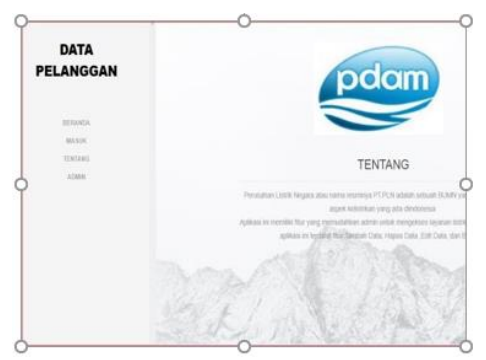


Gambar 9 Tampilan Tentang

\section{E. Form pendaftaran}

Form pendaftaran merupakan tampilan setelah login, form ini berfungsi untuk menginputkan data pertama kali sebelum masuk dalam daftar pelanggan

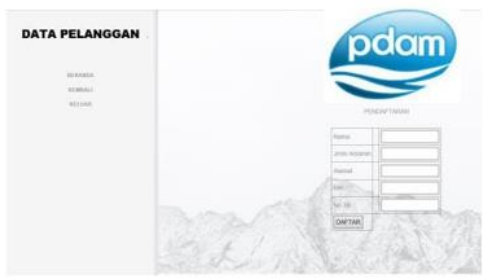

Gambar 10 Tampilan Pendaftaran

\section{F. Form Menu Tambah}

Form menu tambah ini merupakan tampilan yang bisa disebut juga form pendaftaran ke dua setelah pendaftaran awal yang hanya menginputkan nama dan lain-lain. Kalau di form ini pemohon yang ingin pasang baru PDAM dikantor PDAM yang nantinya akan diinput otomatis ke database dan tersimpan didalam sistem dengan memilih daya dan diinputkan no token nya.

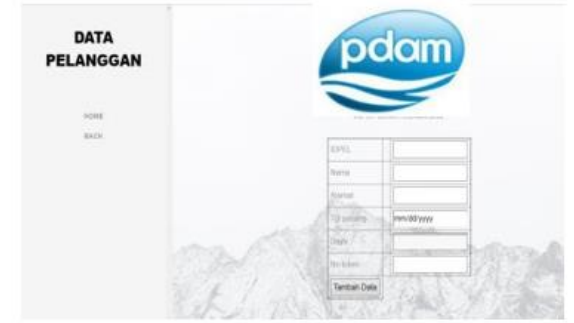

Gambar 11 Tampilan Pendaftaran

\section{G. Form Menu Edit}

Form menu edit berfungsi untuk merubah data didalam tabel .

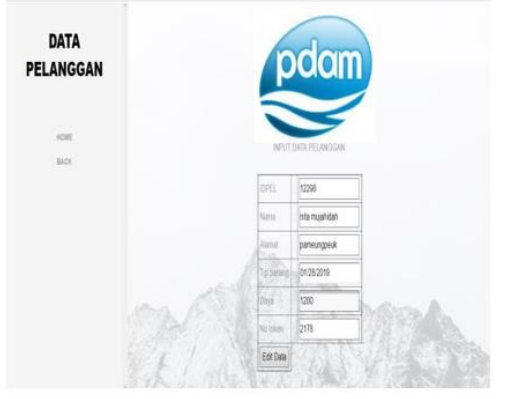

Gambar 12 Tampilan Edit

\section{H. Form Menu}

Form menu berfungsi untuk mencetak sebuah id_pelanggan dan nama nya secara otomatis

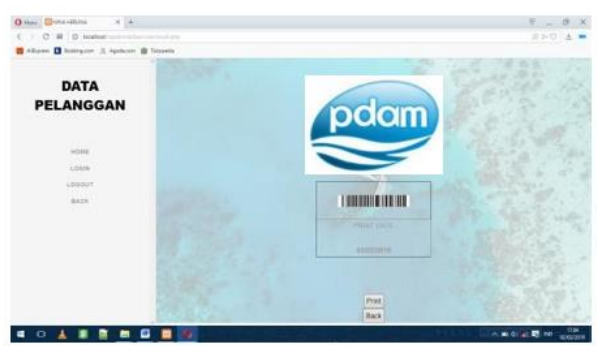

Gambar 10 Tampilan

\section{KESIMPULAN}

Sistem informasi pemasangan baru PDAM berbasis web ini dapat membantu proses input data yang secara langsung akan masuk kedalam database salain itu dapat melakukan pendaftaran baru PDAM serta membantu mengelola data pemasangan baru PDAM agar tidak terjadi penumpukan data dan kesulitan pada saat pencarian data. Sehingga pelanggan mendapatkan pelayanan yang lebih baik.

\section{Daftar Pustaka}

[1] Abidin, M. Z., \& Rachmansyah. (2014). Perancangan

[2] Al Fattah, hanif. 2007. Analisis \& Perancangan Sistem Informasi. Yogyakarta: Andi.

[3] Nurdiana, Dian, and Andri Suryadi. "Perancangan Game Budayaku Indonesiaku Menggunakan Metode MDLC." Jurnal PETIK 3.2 (2017): 3944.

[4] Dina, A. P., Fatoni, \& Yulianingsih, E. (2014). Sistem Pendaftaran Pasang Baru Secara Online Pada PT PDAM (Persero) WS2JB Rayon Ampera Palembang. Jurnal Bina Darma Vol.1 N0. 01, 110.

[5] Sistem Informasi Layanan Pelanggan PDAM Berbasis Website Pada PDAM Rayon Ampera. Jurnal STMIK MDP Vol.1 No.01, 1-10.

[6] Suryadi, Andri. "Perancangan Aplikasi Game Edukasi Menggunakan Metode Waterfall." Jurnal PETIK 3.1 (2017): 8-13.

[7] Suryadi, Andri. "Sistem Rekomendasi Penerimaan Mahasiswa Baru Menggunakan NAIVE BAYES Classiffier di Institut Pendidikan Indoensia." Joutica 3.2 (2018): 171182.

[8] Suryadi, Andri. "Sistem Informasi 
Lembaga Pemasyarakatan Studi Kasus: Lembaga Pemasyarakatan Kelas IIB Kota Garut." Jurnal PETIK 4.2 (2018): 120-127.

[9] Suryadi, Andri, Dian Nurdiana, and Ilmu Pendidikan Garut. "Sistem Pendukung Keputusan Seleksi Ujian Masuk Perguruan

Tinggi Menggunakan NBC (Naive Bayes Classifier)." Kinetik 1.3 (2016): 173- 182.

[10] Suryadi, Andri, and Dian

Nurdiana. "Sistem Pengambilan

Keputusan Untuk Pemilihan Teknisi

Lab Dengan Multi Kriteria

Menggunakan Metode AHP

(Analytic Hierarchy

Process)." Mosharafa: Jurnal

Pendidikan Matematika4.1 (2015): 11-21.

[11] Suryadi, Andri, Erwin Harahap, and Adi Rachmanto. "Rancang Bangun Sistem Informasi Persediaan Obat Berbasis WEB di Apotek XYZ." Jurnal PETIK4.2 (2018): 114-119.

[12] Sutabri, Tata. 2012. Analisa Sistem Informasi. Yogyakarta: Andi. Tjahjono,

B. 2008. Analisis Dan Perancangan Sistem Informasi Pemasangan Jaringan PDAM Baru Pada PT PDAM (Persero) Area Pelayanan Sepatan. Jurnal Fasilkom Vol.6 No.2, 117-125. 